\section{Tropical Diseases in Travelers}

\author{
Eli Schwartz, editor
}

\author{
Wiley-Blackwell, Chichester, \\ UK, 2009 \\ ISBN: 9781405184410 \\ Pages: 485; Price: US \$159.00
}

This book captures the essence of tropical medicine for clinicians evaluating returning travelers. The editor, an international expert in tropical and travel medicine, authored or coauthored many chapters of the book. The book also reflects the experience of numerous experts in the field of travel medicine.

The book consists of 43 chapters organized into 3 sections: general aspects of tropical diseases in travelers, specific infections, and approaches to specific syndromes. The first section describes general trends in travel medicine and discusses types of studies encountered in travel medicine research. This section provides a basis for screening travelers and makes recommendations for doing so.

The section on specific diagnoses dedicates a chapter each to the most commonly encountered groups of microbial organisms. This section emphasizes the epidemiology of travel illnesses and clinical signs and symptoms in travelers, especially aspects of illness different from those of populations residing in the disease-endemic areas. This section also includes photographs of physical findings in travelers; the photographs highlight such diseases as African tick-bite fever, chikungunya, dengue, swimmer's itch, African trypanosomiasis, leishmaniasis, measles, tungiasis, and cutaneous larva migrans.

The section on syndromes focuses on approaches to evaluating major complaints in returning travelers. Complaints discussed include posttravel diarrhea, fever, skin problems, eosinophilia, respiratory complaints, rheumatologic conditions, and neurologic findings.

For clinicians, adequate knowledge of illnesses associated with travel is critical to the ability to provide proper pretravel advice. This book contributes much information to assist in understanding diseases encountered by travelers. It is a valuable reference on tropical and travel medicine and is especially important to clinicians managing ill travelers. However, it also supplies fundamental background information for clinicians providing only pretravel consultations. The authors present concise, solid evidence and practical insights on tropical diseases in travelers. I recommend it highly to clinicians involved in the care of travelers in industrialized and developing countries.

\section{Lin H. Chen}

Author affiliation: Mount Auburn Hospital, Cambridge, Massachusetts, USA

DOI: 10.3201/eid1511.091287

Address for correspondence: Lin H. Chen, Mount Auburn Hospital, Travel Medicine Center, 330 Mount Auburn St, Cambridge, MA 02238, USA; email: 1chen@hms.harvard.edu

\section{Contagion and Chaos: Disease, Ecology, and National Security in the Era of Globalization}

Andrew T. Price-Smith

Massachusetts Institute of Technology Press, Cambridge, MA, USA, 2009

ISBN: 978-0-262-66203-1

Pages: 296; Price: US \$24.00

(paperback)

Contagion and Chaos describes the threat that emerging and reemerg- ing infectious diseases pose to international security because of these diseases' negative effects on sovereign states. The author proposes the following 5 hypotheses: 1) epidemic disease may compromise the prosperity, legitimacy, structural cohesion, and, in certain cases, security of sovereign states; 2) epidemics and pandemics of emerging or reemerging infectious diseases may promote economic and political discord among countries but are unlikely to generate serious armed conflict; 3) only some pathogens threaten national security according to criteria such as lethality, transmissibility, fear, and economic damage; 4) warfare (intrastate and interstate) amplifies problems caused by disease; and 5) the paradigm of health security is philosophically grounded in the political tradition of republican theory.

The author stresses that the association between the health of a population and perception of national security is ancient but largely forgotten. $\mathrm{He}$ suggests that a republican revision of systems-level international relations theory provides an optimal framework for examining the paradigm of health security.

The book's 8 chapters discuss data supporting the author's hypotheses. The first chapter describes the relationships among pathogens, society, and the state from a political science perspective. For nonpolitical scientists, this chapter is difficult. However, chapters 2-7 are interesting and enlightening. Chapter 2 explores the historical relationship between the state and society in the context of contagion. The author provides a historical perspective for the long-held perception that infectious disease poses a distinct threat to the stability, prosperity, material interests, and, therefore, security of the state. Chapters 3-6 present case studies concerning the influenza pandemic of 1918, HIV/AIDS, bovine spongiform encephalopathy and its human variant, Creutzfeld-Jakob disease, and severe acute respiratory syn- 
drome. Each illness is discussed in the context of disease-induced destruction and debilitation of the population, erosion of productivity and prosperity, fear-induced social destabilization, disruption of governance institutions, and the consequent erosion of state power relative to unaffected rival states. In Chapter 7, violent conflict and war are shown to be disease amplifiers through examination of the mechanisms by which interstate and intrastate conflict contributes to disseminating existing pathogens and to emerging novel microorganisms. The final chapter examines the proposition that health contributes to economic prosperity, which bolsters the power of the state. Each chapter has extensive notes to assist the reader.

The author proposes that the best way to curtail future epidemics (and pandemics) is to augment the healthcare infrastructure and improve the health of populations. Fulfilling these needs is particularly important for developing countries where conditions are favorable for disease emergence because of globalization that results in increased population density, ecological degradation, rapid transportation technologies, and mass migration and because of low or nonexistent disease surveillance and containment capacities. This book will be of interest to political scientists and those in public health and medicine because it highlights the interdependence between political science and public health.

\section{Stephen A. Morse}

Author affiliation: Centers for Disease Control and Prevention, Atlanta, Georgia, USA

\section{DOI: 10.3201/eid1511.090577}

Address for correspondence: Stephen A. Morse, Centers for Disease Control and Prevention, 1600 Clifton Rd NE, Mailstop C18, Atlanta, GA 30333, USA; email: sam1@ cdc.gov

\section{Outbreak Investigations around the World: Case Studies in Infectious Disease Field Epidemiology}

\section{Mark S. Dworkin}

Jones and Bartlett Publishers, Inc., Sudbury, MA, USA, 2009

ISBN-10: 076375143X

Pages: 480, Price: US \$64.95

Outbreak investigations are fascinating stories. Mark S. Dworkin, Epidemic Intelligence Service (EIS) Class of 1994, has compiled 19 firsthand accounts of case studies in infectious disease epidemiology and presents them in chronological order. The first is Kenrad Nelson's 1964 investigation of leptospirosis associated with swimming in an irrigation ditch in rural Washington; the last, Patricia Quinlisk's evaluation of a 2006 mumps epidemic in Iowa. In between are investigations involving 8 bacterial infections, 6 viruses, 1 helminth (Taenia solium), 1 protozoan (Cryptosporidium sp.), and a misdiagnosis of Entamoeba histolytica. Fourteen of the outbreaks occurred in the United States; of the remaining 5, one each occurred in Portugal, Israel, Egypt, Gabon, and Liberia.

In general, the stories are told as first-person accounts, use an informal style, and include personal reflections. Many chapters, but not all, include epidemic curves, maps, tables, exhibits, and lessons learned. I especially enjoyed reading about Paul Blake's experience with a cholera outbreak in Portugal, Charles Jennings and measles in Illinois, Daniel Bausch and Ebola in Gabon, and reading both chapters by Jeffrey Davis - toxic shock syndrome and cryptosporidiosis.
As an instructor of epidemiology, I read the book seeking a complementary text for students. The informal style does make enjoyable reading but does not translate into an appropriate textbook. Several of the chapters are too long. One chapter is written by multiple authors, told from 4 points of view, and is very difficult to read. The lessons learned are organized chronologically, not by content. Some lessons are redundant; other areas of epidemiology are not adequately explored, e.g., sampling strategies, study design, questionnaire development and data analysis, population screening, and noninfectious diseases. However, I like the concept of first-hand accounts to supplement epidemiology textbooks. Could one format the chapters as unknowns like that of New England Journal of Medicine case studies? Could outbreak investigations be written in the style of Berton Roueché as medical mysteries, but supplemented with epidemic curves, maps, and lessons learned?

I recommend this book to all infectious disease epidemiologists, EIS officers, and infectious diseases clinicians interested in the aura of outbreak investigations. I also encourage the editor to consider a reformatted second edition to enhance the book's usefulness as a complementary text in epidemiology coursework.

\section{Harry W. Haverkos}

Author affiliation: Uniformed Services University of the Health Sciences, Bethesda, Maryland, USA

DOI: 10.3201/eid1511.090931

Address for correspondence: Harry W. Haverkos, 15328 Bitterroot Way, Rockville, MD 20853 USA; email: haverkosh@comcast.net

The opinions expressed by authors contributing to this journal do not necessarily reflect the opinions of the Centers for Disease Control and Prevention or the institutions with which the authors are affiliated. 